\title{
Cross-Disciplinary Exploration and Application of Reflection as a High I mpact Pedagogy
}

\author{
Sarah E. Summers, PhD* \\ Assistant Professor, Department of Humanities and Social Sciences \\ Rose-Hulman Institute of Technology \\ Heather C.S. Chenette, PhD* \\ Assistant Professor, Department of Chemical Engineering \\ Rose-Hulman Institute of Technology \\ Ella L. Ingram, PhD \\ Associate Professor, Department of Biology and Biomedical Engineering \\ Rose-Hulman Institute of Technology \\ Jay P. McCormack, PhD \\ Associate Professor, Department of Mechanical Engineering \\ Rose-Hulman Institute of Technology \\ Patrick J. Cunningham, PhD \\ Associate Professor, Department of Mechanical Engineering \\ Rose-Hulman Institute of Technology \\ *The first two authors contributed equally.
}

Reflection is a high-impact practice in education. This paper explores the premise, approach, and outcomes of a learning community centered on scholarly engagement with the literature of reflection. Using the reflection model operationalized by a national consortium, we developed, implemented, and assessed reflection activities designed to create opportunities for transfer of skills and conceptual change. Two case studies reveal commonalities in using reflection

in a college setting. We explore the questions that emerged as a result of our experiences, and connect this work to the importance of engaging with colleagues in a community of learners.

The practice of reflection connotes an informal and individual practicesometimes seen as unstructured or emotional. Yet, far from being amorphous, reflection is a "systematic, rigorous, disciplined way of thinking with its roots in scientific inquiry" (Rodgers, 2002, p. 845) that involves sharing and critical dialogue within a supportive environment. Ambrose (2013) suggested that true learning requires reflection on acts of doing or practicing what one is trying to learn, a suggestion consistent with the idea that reflection is a cyclical process promoting continuity of experiences (Rodgers, 2002). Given its rigor and application to experiential learning, reflection complements the goals and approaches of STEM education; however, we find that traditional STEM education regularly omits opportunities for explicit training and practice with this formal process of reflection.

Reflection is a high impact educational practice, with successful applications across disciplines, especially in professional practice settings (e.g., architecture, nursing, law, and management; see Fook, White, \& Gardner, 2006; Schön, 1987). However, much of this work describes idiosyncratic models and thus presents a challenge to educators who desire a clear path to implement reflectionbased learning practices. To help educators meet this challenge, the Consortium to Promote Reflection in Engineering Education (CPREE), a nationally distributed, twelve institution collaboration, operationalized the theoretical constructs presented by Dewey, Rodgers, and others to an actionable model. In the CPREE model, reflection is "an intentional form of thinking where a learner becomes aware of and revisits aspects of an experience with a lens for meaning-making, contributing to 
certain future effects" (Turns, Sattler, Yasuhara, Borgford-Parnell, \& Atman, 2014, para. 3). Distributed as the core model of the consortium, the operationalized model provides a framework for scholarly teaching (see Figure 1), and helps educators use reflection in the classroom.

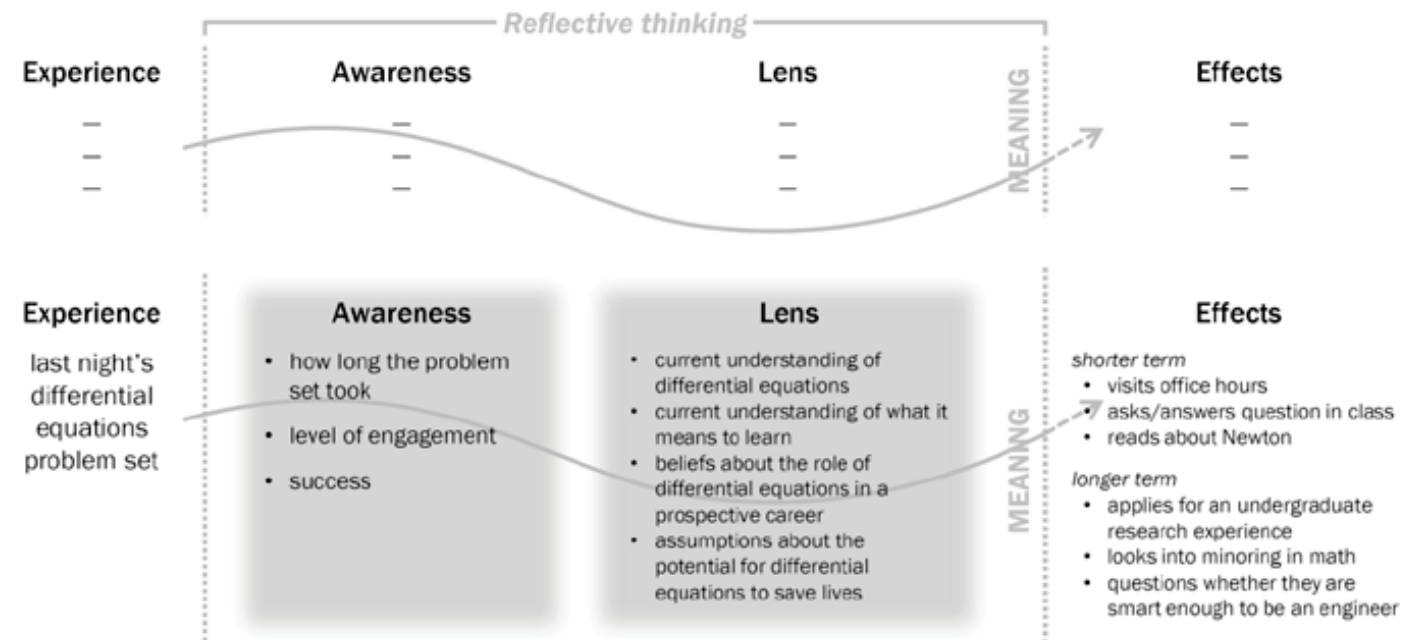

Figure 1. Operationalized model of reflection (description from Turns et al., 2014, image from CPREE used with permission).

As educators, we construct or impose experiences on our students (the left side of Figure 1). Through the prompts we use, we direct students' awareness to specific features of the experience and help them analyze the experience with a particular lens (i.e., content, development as learner, meaning making, or development of identity, as in Grossman, 2009). Our direct influence ends with this support, leaving us with only indirect influence on the future effects. To provide guidance with the operationalized model, we present (and used ourselves) the following questions to guide the support we provided learners in each phase of the reflection process. Experience: What is the experience being reflected upon? What are students focused on? What aspect(s) of the experience are students considering? Awareness: What is done to support students' awareness of the experience? Lens: In this reflection activity, are you supporting students' reflection on their: (a) accountable disciplinary knowledge, (b) identity, or (c) preparing for future learning? Effects: What meaning do students arrive at as a result of the reflection activity? How does the activity position students for action? What are likely actions that students can take after completing this activity? (B. Sattler, personal communication, January 29, 2015; L. Thomas, personal communication, February 17, 2016). These questions naturally create a cyclical process, as future effects become new experiences, which provide fodder for additional reflection. Further, these questions illustrate the organized nature of both preparing students for reflection and of the acts of reflection.

In the sections that follow, we detail our small, private STEM institution's application of the operationalized model through a summer learning community (LC). We provide a brief overview of the LC and of the reflection activities that this community built using the operationalized model, including our approach to assessment. Then, we provide two case studies of assignments designed and implemented by LC participants-one in the Humanities and one in Chemical Engineering. Finally, we examine our experiences integrating reflection-focused learning into a STEM curriculum and outline the questions prompted by that examination. 


\section{Reflection Learning Community}

As scholarly educators, we understand the value of community and constructivist approaches when working with new ideas (Rodgers, 2002). Therefore, as part of our campus CPREE activities, Ingram, Cunningham, and McCormack created the LC during the summer of 2015 to develop reflection activities that were integrated with existing courses and student experiences. Twelve participants comprised the LC, representing engineering (Chenette), math, humanities (Summers), institutional research, and global programs. The group met six times during the summer, with a poster session at the start of the next academic year. The major activities of the LC supported growth and exploration (see Appendix A), and the group used the core principles of disciplinary diversity, topic-based focus, theoretical base in teaching and learning, high collaboration, and time investment, consistent with the guidance provided by the research collected in Richlin and Cox (2004). Participants critiqued peer activities, debated applications to various courses, discussed philosophical foundations, and reconsidered experiences with students. More information on the structure, operations, and funding of the LC is available upon request from the authors.

The LC had the explicit goal of including reflection activities across a variety of experiences for our STEM-focused students. We observed several key outcomes from the LC experience. Each educator created a scheme for students to experience the totality of the reflection structure (see Figure 1). Informed by the literature and constructive peer critiques, all

To refine their approaches to learning, learners engage in reflection on how they are processing information, i.e., metacognition. implement these activities in the next iteration of their course. For readers interested in examples, more than 100 reflection-based activities are available via the CPREE field guides archived at http://cpree.uw.edu/about-fieldguides/.

The reflection activities designed by LC participants exhibited a range of practices. These activities focused on specific content, development as a learner engaging with content, making meaning of the content, or developing a sense of identity (Grossman, 2009). In reflecting on content, learners develop deeper learning by discovering relationships between and among concepts or the function or role of a topic within a larger framework. To refine their approaches to learning, learners engage in reflection on how they are processing information, i.e., metacognition. In making meaning of the content, learners focus their attention on why the content is important to the discipline or why it matters to them individually. Identity development occurs when learners reflect on their experiences through a particular lens (e.g., the discipline) and formulate both an affiliation and a sense of uniqueness. Each emphasis Grossman identifies is consistent with a deep approach to learning (Marton \& Säljö, 1976).

\section{Assessment of Reflection}

The initial opinion of many educators (including participants in our LC) is that assessment of reflection is inherently problematic for a variety of reasons. Through our work in the LC, and with guidance from the literature (e.g., Moon, 2006), we rejected that opinion in favor of a scheme proposed by Kember and colleagues $(1999,2008)$ that focuses on written work. The revised scheme (Kember, McKay, Sinclair, \& Wong, 2008) relies on four levels of analysis, most briefly summarized as non-reflection, understanding, reflection, and critical reflection. Detailed descriptions are included in Kember et al.'s (2008) work; here we provide our own short synopses. 
In applying this assessment approach, we adopted four premises. First, we acknowledged that we can only assess what is produced in writing, knowing that this production almost certainly would not capture the entirety of a student's experience. Second, we accepted Creswell's (2007) rationale for not focusing on the quantitative distribution of student responses in each category: counting responses creates an orientation to "magnitude and frequency contrary to qualitative research" (p. 152). In this case, what the responses demonstrate about students' abilities to practice reflection matters more than the distribution of student responses across categories. Third, we noted that our language and assessment illustrated comparative value of the categories with respect to reflection only; we accepted that for many educational tasks and in many different settings, different levels of engagement with the content or experience occur. Finally, we recognized that ratings of Reflection and Critical Reflection did not guarantee reflection and ratings of Non-Reflection and Understanding did not preclude the presence of reflection, as noted by Moon (2006). Any measure of an internal process will be imperfect, but even in its lack of precision, such measures still are indicators of reflection. Using this defined assessment scheme was in keeping with our conceptions of reflection as a rigorous cognitive activity going beyond emotional responses and imprecise feelings.

Non-reflection (or habitual action in the Kember et al., 2008 formulation) is characterized by rote thinking, most often illustrated by a "just the facts" statement or answer. Calculation, routine experiences, procedural activity, significant paraphrasing, and other similar activities can exemplify this level of thinking. The category understanding presents a learner's search for meaning within the confines of the conceptual system. Analogous to the revised Bloom's taxonomy category "understand," learners displaying this category of thinking would be competent as judged by a concept inventory but likely struggle to translate a concept in one system to a new situation. Reflection is displayed by learners who incorporate concepts or experiences into a larger knowledge scheme. In general, some or all of three features are present in reflection-focused statements: application of concepts or theories, connection to personal experience, and insight regarding learning. Critical reflection is illustrated by "a change in perspective over a fundamental belief" (Kember et al., 2008, p. 375). To be indicative of this category of reflection, written submissions present an explicit awareness (often newly discovered, as it is so ingrained) of the "fundamental belief" (p. 375) and an exploration of why that belief is no longer satisfactory given the new learning or experience.

In the case studies provided, each instructor used the Kember et al. (2008) rubric to assess her students' responses, matching specific elements of the rubric to explicit student phrases. We found substantial differences among the written submissions we examined in terms of the amount of meaningful content presented. We observed the general pattern that as written work fit more into the reflection and critical reflection categories, the submission required more words on the student's part, because these two categories require providing unique personal context and insight. To show the range of student experiences with this pedagogy, we present an illustrative example within each of the rubric's categories. Our intent was not to prove the point through exhaustive examples, but to highlight the opportunities inherent in the reflection approach to impact student thinking. One goal of the educational enterprise is to cause more students to experience significant thinking about themselves, content, and experiences. The case studies below illustrate two mechanisms for achieving this goal. Our work explores a single point in time, and we are eager for other scholarly research to illuminate the longterm impacts of structured reflection practices, such as those described below, in STEM education. 


\section{Case Study: Reflective Writing in Technical Communication (Summers)}

One of the biggest challenges I face when teaching Technical and Professional Communication (Tech Comm, a required, upper-level writing course), is how to help students transfer the skills and knowledge they gain from my course to the myriad writing tasks they will encounter in future educational and professional situations (Yancey, Roberson, \& Taczak, 2014). Students incorrectly conceptualize transfer of writing knowledge as directly applying a skill from one task to another (e.g., once they have learned one way to design a PowerPoint slide, they can replicate that slide design for any presentation). In fact, transfer of writing knowledge requires understanding that existing skills and practices must be adapted and repurposed for new contexts. To move transfer beyond the limited scope of tasks, instructors must develop both students' dispositions toward learning and their ability to understand their learning in context (Wardle, 2007). Reflection, as operationalized by CPREE, addresses both students' dispositions toward learning and their ability to understand that learning in context. Thus, reflection directly promotes both the dispositions and the contextual awareness that successful transfer requires.

My course, like many technical writing courses, includes juniors and seniors from a wide range of disciplines and with varying professional goals. In a single, ten-week course, I cannot teach all students how to write every discipline-specific document they might encounter. Instead, I provide students with assignments that reinforce a rhetorical approach to writing-a focus on audience, context, and clarity in writing and document design. To apply these concepts beyond the course, students must identify how these ideas intersect with the

...reflection directly promotes both the dispositions and the contextual awareness that successful transfer requires.

norms in their fields and how to best repurpose them in new situations. Given this context, I participated in the learning community with this question: How can I use reflection expressed in writing to encourage students to draw connections between the writing tasks or rhetorical concepts in Tech Comm and writing in their disciplines as a means of promoting transfer?

As a result of the LC, I designed a Reflective Professional Writing Portfolio assignment and implemented it in two sections of Tech Comm (Appendix B). The portfolio assignment had components pulled from the operationalized model. First, students selected at least three pieces of writing or design related to their disciplines (called artifacts in the assignment, representing the original experience) and wrote abstracts to accompany each artifact. In these abstracts, students provided the context for the artifact (illustrating awareness) and then explored the writing and rhetorical skills they demonstrated in the artifact (providing a lens) and how those writing and rhetorical skills might be more broadly applied in their disciplines or future professional settings (leading to effects). Next, students used the experience writing abstracts to describe what they learned about their communication skills from completing the portfolio (illustrating awareness) and create a communication philosophy (providing a lens). The ultimate aim of the philosophy was an analysis of how students can apply their philosophy to future contexts (predicting effects). Finally, students created websites to display their portfolios and to practice professional writing and design in an online context-itself an act of transfer.

\section{Student Outcomes}

Using Kember et al.'s (2008) scheme, I analyzed the quality of students' portfolios and determined to what extent they understood the connections between their experiences and specific writing tasks or communication approaches. This analysis demonstrates the range of student reflection and highlights the possibilities for transfer among students who reach reflection and critical reflection. 
Non-reflection. Very few student portfolios fell into the category of nonreflection. Those portfolios that did often replicated parts of the assignment sheet or examples from class and seem focused on providing an objective "right" answer, rather than providing a unique and personal reflection on a past writing experience. For example, in an abstract of a lab report, one student wrote: "This lab demonstrated three qualities that are important as a chemical engineer working alongside chemical manufacturers: attention to detail, problem solving skills, and proper development skills. These skills are necessary to ensure the efficient production of high quality products." The student only discussed the report in terms of its objectives, rather than in terms of the student's experience attempting to achieve those objectives. Additionally, this student concluded each of her abstracts with the same final sentence about necessary skills, which demonstrates a lack of attention to different contexts she might encounter. In non-reflection, students saw writing experiences as objective outcomes and could only articulate superficial connections to future contexts, which suggested they will not be successful transferring writing knowledge.

Understanding. In this category and context, students considered the connections between the experience and the lens; however, the understanding of that connection relied heavily on repeating the theory underneath the lens. For example, in his communication philosophy, one student explained the relevance of the rhetorical triangle, a model that helps students understand the relationships between writer, audience, and message:

When I described catering to the audience earlier, I referenced the two sides of the triangle that share the audience as a point. It is important to verbally communicate to the audience in a way they will understand and also design the message so that it has significance with the audience.

This student was clearly able to recall his past presentation experience and apply the lens of the rhetorical triangle. Yet, his writing lacked specific references to context or personal understanding of the lens. How did the student determine the audience's needs? How did the student design the message to appeal to that specific audience? Without answering these context-specific questions, the student was unable to make meaning from the experience and apply it to future action. Understanding is an important first step toward being able to transfer writing skills, but students in the understanding stage would be unlikely to clearly articulate differences in contexts and the appropriate strategies to account for those differences.

Reflection. This practice occurred when students applied the lens of rhetorical theory to their experiences and created personal meaning. Many students attained reflection in at least one of their abstracts because they explicitly practiced structuring abstracts this way in class. In collaborative writing activities, we composed examples that began with describing the context of an experience, applied a concept from class (like attention to audience or timeliness), and then explained why that application was important to their learning, their fields, or their careers. For example, the following example from a student's abstract about a group presentation makes more specific applications of course concepts than the "understanding" example:

A highlight of this project was our use of the assertion-evidence method of presenting. This method allows the presenter to highlight key information and main ideas for the audience without putting too much on the slide. It also allows the presenter to expand upon his/her ideas-better engaging the audience, showing his/her expertise in the subject, and forcing the listeners to focus on the speaker rather than only the slides. Working as a 
doctor/engineer it will be important for me to be able to work in a team as well as present my findings in a way that is concise and engaging for both technically and non-technically versed audiences.

The student reflected on the strength of his project by explaining his own understanding of the benefits of a design approach and the ways those benefits connect to a rhetorical emphasis on audience. Then, the student considered how this approach might apply to his future career. While we cannot know exactly how the personal insight he gained here will aid him in the future, we know that regardless of his future discipline, he will be able to apply the cross-disciplinary skill of communicating for a specific audience.

Critical reflection. Relatively few students reached critical reflection in their portfolios, as Kember et al. (2008) predicted. Critical reflection requires a "change in perspective" (p. 379) based on reflection. For many students, this change may not occur until they must apply and revise their existing writing knowledge. However, a few students articulated changes they have noticed already in their approach to writing, including one student, who contrasted previous internship projects with current course projects in his communication philosophy:

During this internship, I presented multiple projects while using my old slide-making habits. Over the past quarter, I have greatly developed my ability to design presentation slides using the "rhetorical triangle" by keeping the reader/viewer as the driving factor of the design. I have also used this same factor in developing instruction manuals at both [internship company] and in the classroom. Furthermore, my skill to describe instructional steps in a very effective manner grew tremendously this past summer creating step-by-step assembly line processes; however, my organization and design of these steps was lacking. A key skill I learned during this past quarter was my ability to organize the manuals more effectively. Features of this organization include incorporating pictures in a strategic aspect, as well as keeping the same blocked format to articulate each instructional step.

This student considered past internship writing experiences through the lens of the rhetorical triangle and key design concepts, and he demonstrated that he shifted his perspective on what he considers good work. Through reflection, the student realized that, while the content of his instruction manuals was "effective," the design needed improvement. He was also able to articulate strategies for improving design that can be applied to new contexts. This student's critical reflection hinged on extensive experience writing in a workplace; thus, other students might reach critical reflection on their own-having already practiced the process of reflectiononce they encounter more writing contexts.

\section{Case Study: Reflection to Make Sense of Predictions in Engineering (Chenette)}

Conceptions about heat and mass transfer are informed by our experience with the world (e.g., when should one use salt to "melt the ice" on a winter day?), yet students struggle to conceptualize thermal and chemical properties of materials. Students find it easy to justify why a system behaves as it does based on experiential knowledge alone. However, if that experiential knowledge contains a misunderstanding, the dichotomy between one's intuition and the accepted scientific explanation may result in conflicting information. A shift in understanding must take place to align intuition with what makes sense from a scientific perspective. Unfortunately, for thermal energy concepts, this shift often fails to happen even after college-level instruction; thus, misconceptions persist (Prince, Vigeant, \& Nottis, 2012b). In previous versions of my Fundamentals of Heat and Mass Transfer 
course, I confirmed the absence of such a shift via a concept inventory, demonstrating only an average normalized gain of $8 \%$, consistent with other research (Prince et al., 2012a).

Conceptual change requires both dissatisfaction with the original concept and recognition of an intelligible new concept (Posner, Strike, Hewson, \& Gertzog, 1982) and is related to the act of reflection. Knowing that conceptual change was necessary in my context, I wanted to explore if and how written reflection activities facilitated creating the required dissatisfaction and recognition needed to adjust commonly-held misconceptions about heat and mass transfer. For example, most students can correctly identify and employ the proper relationships to model a system that involves the transfer of energy, but only around $20 \%$ correctly identified the effect the material properties had on temperature profile within the object. This situation was ideal for using reflection to explore content knowledge (Grossman, 2009).

I introduced in-class prediction activities related to heat transfer, as recommended by Vigeant, Prince, and Nottis (2011). Three activities were distributed across a 10-week course. The one I highlight here focused on conduction of heat to melt ice (see Appendix C). For each activity, I described a heat transfer scenario and asked the class questions about heat transfer processes, asked students to make a prediction, allowed students to participate in preparing and observing a simple demonstration (the experience), and led a short classroom discussion. Within the week following the in-class activity, I assigned students to complete a follow-up assignment in the form of an online quiz that prompted students to revisit the activity and answer nine questions in a couple of sentences each. To frame student awareness, I offered no guidance other than the number of sentences on how students should respond to questions, asking only that they put forth a good-faith effort to complete it. Students received full credit if they completed the follow-up assignment, regardless of effort, correctness, or length of responses. The assignment was worth one problem on a homework assignment. The prompting statements for the follow-up assignment were based on the Rate vs Amount Misconception Survey (AIChE Concept Warehouse, n.d.) These guiding statements (see Table 1) loosely map to the steps in the operationalized model of CPREE (see Figure 1). Appendix C provides the actual follow-up assignment questions, which included asking students to describe a new understanding of the experience (lens) and making conclusions about a new scenario (effects). I purposefully did not call this a "reflection" assignment to avoid negative connotations that students may have for such assignments.

Table 1

Prompting Questions Asked After Each In-class Prediction Activity

\begin{tabular}{ll}
\hline Aspect & \multicolumn{1}{c}{ Prompting Question } \\
\cline { 1 - 1 } Experience & Recall the prediction activity in class. Re-state your prediction. \\
Lens & Describe what you observed during the demonstration. \\
& $\begin{array}{l}\text { If the results of the demonstration did not match your initial } \\
\text { prediction, create a new explanation of the results. In your } \\
\text { explanation, you should pay particular attention to why your } \\
\text { prediction was incorrect and how you revised your thinking to } \\
\text { explain what happened. }\end{array}$ \\
Effects & $\begin{array}{l}\text { Do factors that increase the rate of heat transfer always increase } \\
\text { the amount of heat transfer too? Yes/No, Explain. What, if } \\
\text { anything, did you learn from this activity? }\end{array}$ \\
\hline
\end{tabular}




\section{Student Outcomes}

I adopted the four-category rubric developed by Kember et al. (2008) to assess student responses with respect to the quality of reflection. Evidence of reflection often appeared in response to the final prompting question, "What, if anything, did you learn from this activity?"

Non-reflection. Responses categorized as non-reflection simply reproduced the theory discussed in class. For most students, this reproduction implied a functional understanding, but their written statements showed no attempt to reach a greater understanding of the topic or find deeper meaning from the experience. For example, the following two students mentioned what they learned, but their conceptual understanding was unclear: "[I learned] that the amount of heat transferred is related to mass"; "I learned that there is a difference between heat rate and the amount of heat transferred." The low specificity of the language used by these two students illustrated the bare minimum in conceptual understanding. In the first case, the student missed the important aspect of the concept that amount of heat transferred is proportional to mass. Neither student addressed the reason behind their observation.

Understanding. Student work that correctly articulated the point of the activity, but only provided responses within the context of the topic demonstrated understanding. For example, "This activity helped me see the physical differences in amount of heat transferred and the rate of heat transfer. It shows the reason why someone defined the heat flux on a per area basis. It was a helpful activity." This example illustrated more appropriate terminology and the additional conceptual understanding of the parameters influencing heat flux. The statement focused on only the specific context addressed in the demonstration and was consistent with a minimally acceptable response on a quiz or exam.

Reflection. Responses that exhibited reflection included some personal insight or applied what students learned to a real-life scenario. For example, one student wrote:

I was able to learn the advantages of controlling exposed surface area. For instance, if someone wants their drink to get colder faster, they should use crushed ice. If someone wants their drink to stay cold longer, they should probably use cubed ice.

This response addressed a key aspect of the overall demonstration and considers better in different contexts. The student found meaning in the applicability of the concept to a different setting, while remaining firmly within the boundaries of the concept itself.

Critical reflection. Student work that exhibited critical reflection showed "evidence of a change in perspective over a fundamental belief" (Kember et al., 2008 , p. 379) pertaining to the distinction between the rate of heat transferred and the amount of heat transferred. One student acknowledged the prediction was wrong and described a change in understanding: "I thought it had to do with volume [per piece] of the cubes but in reality it was the mass that mattered and because both masses were the same they both dropped the water to the same temperature." The student went on to identify a broader lesson learned from this activity:

I learned that changing your prediction based off of results is not a bad thing. I also learned that what you take away from an event should be how and why they work not if you were right or wrong. 
This student explored two levels of Grossman's (2009) reflection-considering the conceptual content in new ways, and considering her learning in new ways. The student hinted at applicability of the experience to new contexts, fitting the effects component of the operationalized model. This type of thinking is promoted by reflection-focused activities in a way that solving equations or reading textbooks do not. I noted that among students who believed their original predictions about the melting ice were completely correct, none exhibited critical reflection.

\section{I nstructor I mpressions}

Summers and Chenette worked together to consider their experiences using reflection in the classroom through the scholarly lens provided by the resources from the LC. In this section, we consider the meanings we can make from our experiences and the ways they can shape teaching practices.

As we discussed our assignments and our students' responses, we realized that we took two very different approaches to integrating reflection into our classrooms. Summers taught reflection explicitly, including lessons on reflective writing and using CPREE materials to help students understand how reflection might

As instructors, we are responsible for creating the learning opportunities, but students must do the work themselves. benefit them as writers and learners. Thus, reflection was a core part of the content of the portfolio assignment. In contrast, Chenette used reflection to teach content. She used minimallyguided reflection as a way to encourage students to review their interpretation of heat and mass transfer concepts to see if this process improved conceptual understanding. Thus, reflection can be adapted to fit instructors' needs across disciplines. Our experiences suggest that reflection can be useful both in teaching specific content and in teaching an approach to learning and thinking, consistent with the framing Grossman (2009) provides.

Despite our different approaches, we both had students submit work that encompassed all of Kember et al.'s (2008) categories, from non-reflection to critical reflection. This distribution in responses suggests that focused instruction can play an important role in improving the quality of student reflection, as it did for Summers' students, but that other factors also can influence the quality of students' reflections. As instructors, we are responsible for creating the learning opportunities, but students must do the work themselves. What students gain from a learning activity depends on the students' engagement with it, their understanding of the material, and the idiosyncratic nature of their previous experiences. For example, Summers noticed that students with prior internship experiences were better able to reflect on the relevance of their writing experiences in professional contexts. Chenette noticed that students with initial predictions that were not completely correct were more suited to expressing personal insights and changes in beliefs. Instructors can provide valuable guidance in finding the appropriate touchstone experiences or manufacturing such experiences for their students.

Given these observations, we developed questions to help us guide our future teaching practices.

1. How much time should we devote to reflection activities and instruction about reflection in the classroom? We both had to rearrange-and at times cut-content to incorporate reflection activities. We want to continue to study student outcomes to determine to what extent time spent discussing or practicing reflection helps students achieve other course outcomes. We recognize that spending time on reflection comes with a cost. A critical issue for instructors is to balance the cost and gains of using reflection as a deep learning pedagogy. 
2. How can we determine to what extent reflection activities influence students' future learning? Whether we are focused on later performance in the course and course sequence (Chenette) or the transfer of course content into new contexts (Summers), we hope to find ways to assess the longer term efficacy of reflection. Such assessment requires longitudinal research.

3. What is the role of guided writing assignments in reflection? Writing seems like the clearest way to assign and assess reflection (e.g., essays as in Kember et al., 2008; journals as in Moon, 2006; and portfolios and other forms as in Wald, Borkan, Taylor, Anthony, \& Reis, 2012), but we also want to investigate the other ways that students process reflection. For example, among students who did not complete written assignments, Chenette observed evidence of some students trying to apply their interpretations to new situations. This outcome seemed to result from the nature of inductive learning, which is inherently hands-on and intriguing.

4. To what extent must reflection be transparent, explicit, and motivated in the specific course setting to positively affect students? The two approaches highlighted in this paper stand in stark contrast. Yancey (2015) argues that even in writing courses, reflection is often "a marginal activity [...] expected from students rather than designed into the curriculum" ( $p$. 189). We wonder if for students to benefit from reflection, they need to know that it is happening. Summers framed the portfolio assignment as a reflective writing task from the beginning and shared theories of reflection (including the operationalized model) throughout the assignment. Chenette avoided all mention of reflection. We are left wondering the importance of explicitness for the different types of reflection specified by Grossman (2009).

\section{Summary}

The complex history of reflection in education and the initial confusion we felt regarding the implementation, assessment, and student experience of reflection resolved through our engagement with the scholarly community. When we take a meta-reflection view, we can see in our collective work the various aspects of Grossman's (2009) reflection categories. With respect to content, we explored what reflection is and how it works, via the literature and the operationalized model. As learners, we developed approaches for engaging with philosophical content well outside our disciplinary expertise. In making meaning, we incorporated our personal philosophies and teaching experiences with our developing understanding of reflection. The LC also impacted our identities as scholarly teachers, through our engagement with peers and with research in the realm of reflection. We came to the broader understanding of the importance of working with colleagues across disciplines and engaging in topics as novices, both having the effect of challenging strongly held positions and facilitating significant growth. As a result of the experiences described here, we can honestly present ourselves as willing and able to do the hard work necessary to ourselves achieve the outcomes we want for our students.

\section{Acknowledgements}

This research aspect of this project was completed with IRB approval to Summers, Chenette, and Ingram (protocols RHS0237 and RHS0254). This material is based on work supported by The Leona M. and Harry B. Helmsley Charitable Trust through funding of the Consortium to Promote Reflection in Engineering Education (CPREE), a collaboration of twelve educational institutions. We especially thank Dr. Lauren Thomas for her contributions to the theoretical framing of this work and for reviewing a draft. We thank Dr. Rachel McCord for early assistance with 
assessment of reflection, and two anonymous reviewers and Kelly Myer Polacek for comments that improved this manuscript. The members of our LC were invaluable in creating the context for this work to occur.

\section{References}

AlChE Concept Warehouse. (n.d.). Rate vs amount misconception survey. AIChE Education Division Concept Warehouse website:

https://jimi.cbee. oregonstate.edu/concept _warehouse/

Ambrose, S. A. (2013). Undergraduate engineering curriculum: The ultimate design challenge. The Bridge: Linking Engineering and Society, 43, 16-23. Retrieved from https: //www.nae.edu/Publications/Bridge/ 81221/ 81228.aspx

Creswell, J. W. (2007). Qualitative inquiry $\&$ research design: Choosing among five approaches ( 2 nd ed.). Thousand Oaks, CA: SAGE.

Fook, J., White, S., \& Gardner, F. (2006). Critical reflection: A review of contemporary literature and understandings. In S. White, J. Fook, \& F. Gardner (Eds.), Critical reflection in health and social care (pp. 3-20). Maidenhead, Berkshire, UK: Open University Press.

Grossman, R. (2009). Structures for facilitating student reflection. College Teaching, 57, 15-22.

doi: $10.3200 / \mathrm{CTCH} \cdot 57.1 .15-22$

Kember, D., McKay, J., Sinclair, K., \& Wong, F. K. Y. (2008). A four-category scheme for coding and assessing the level of reflection in written work. Assessment \& Evaluation in Higher Education, 33, 369379. doi: 10.1080/02602930701293355

Kember, D., Jones, A., Loke, A., McKay, J., Sinclair, K., Tse, H., \& Yeung, E. (1999). Determining the level of reflective thinking from students' written journals using a coding scheme based on the work of Mezirow. International Journal of Lifelong Education, 18, 18-30.

doi: $10.1080 / 026013799293928$
Marton, F., \& Säljö, R. (1976). On qualitative differences in learning. Ioutcome and process. British Journal of Educational Psychology, 46, 4-11. doi: $10.1111 /$ j.2044-

8279.1976.tb02980.x

Moon, J. A. (2006). Learning journals: A handbook for reflective practice and professional development (2nd ed.). New York, NY: Routledge.

Posner, G. J., Strike, K. A., Hewson, P. W., \& Gertzog, W. A. (1982). Accommodation of a scientific conception: Toward a theory of conceptual change. Science Education, 66 ,

doi: $10.1002 /$ sce. 3730660207 211-227.

Prince, M. J., Vigeant, M. A., \& Nottis, K. E. K. (2012a). Best paper PIC IV: The use of inquiry-based activities to repair student misconceptions related to heat, energy, and temperature. Paper presented at the annual meeting of American Society of Engineering Education, San Antonio, TX. Retrieved from https://peer.asee.org/21014

Prince, M., Vigeant, M., \& Nottis, K. (2012b). Development of the Heat and Energy Concept Inventory: Preliminary results on the prevalence and persistence of engineering students' misconceptions. Journal of Engineering Education, 101, 412-438. doi:

10.1002/j.2168-9830.2012.tb00056.x

Richlin, L., \& Cox, M. D. (2004). Developing scholarly teaching and the scholarship of teaching and learning through faculty learning communities. New Directions for Teaching and Learning, 2004(97), 127-135.

doi: $10.1002 /$ tl.139 
Rodgers, C. (2002). Defining reflection: Another look at John Dewey and reflective thinking. The Teachers College Record, 104, 842-866. Retrieved from http://www.tcrecord.org/About.asp

Schön, D. A. (1987). Educating the reflective practitioner. San Francisco, CA: Jossey-Bass.

Turns, J. A., Sattler, B., Yasuhara, K., Borgford-Parnell, J. L., \& Atman, C. J. (2014). Integrating reflection into engineering education. Paper presented at the annual meeting of American Society of Engineering Education, Indianapolis, IN. Retrieved from https://peer.asee.org/20668

Vigeant, M. A. S., Prince, M. J., \& Nottis, K. (2011). The use of inquiry-based activities to repair student misconceptions related to heat, energy, and temperature. Paper presented at the annual meeting of American Society of Engineering Education, Vancouver, British Columbia, Canada. Retrieved from https://peer.asee.org/18483
Wald, H. S., Borkan, J. M., Taylor, J. S., Anthony, D., \& Reis, S. P. (2012). Fostering and evaluating reflective capacity in medical education: Developing the REFLECT rubric for assessing reflective writing. Academic Medicine, 87, 41-50.

doi: 10.1097/ACM.0b013e31823b55fa

Wardle, E. (2007). Understanding 'transfer' from FYC: Preliminary results of a longitudinal study. WPA: Writing Program Administration, 31, 65-85. Retrieved from http://wpacouncil.org/journal/index.htm I

Yancey, K. B., Roberson, L., \& Taczak, K. (2014). Writing across contexts: Transfer, composition and sites of writing. Logan, UT: Utah State University Press.

Yancey, K. B. (2015). The social life of reflection: Notes toward an ePortfoliobased model of reflection. In M. E. Ryan (Ed.), Teaching reflective learning in higher education (pp. 189-202). New York, NY: Springer. 


\section{Appendices}

\section{Appendix A}

Learning Community Outline of Sessions

\begin{tabular}{|c|c|c|}
\hline Session & Session Objectives & Pre-Meeting Homework \\
\hline Introduction & $\begin{array}{l}\text { Establish baseline rapport with } \\
\text { their colleagues; Analyze the } \\
\text { operational definition of } \\
\text { reflection; Deliver a three } \\
\text { minute summary of their } \\
\text { anticipated project. }\end{array}$ & Read Felton et al. (2013). \\
\hline $\begin{array}{l}\text { Foundational } \\
\text { Concepts }\end{array}$ & $\begin{array}{l}\text { Explain key aspects of } \\
\text { reflection experiences; Create } \\
\text { a master document of relevant } \\
\text { terms, issues, considerations; } \\
\text { I dentify initial conceptions of } \\
\text { what reflection can and can't } \\
\text { do; Consider the range of } \\
\text { reflection "tools" available and } \\
\text { scenarios for deployment of } \\
\text { these "tools". }\end{array}$ & $\begin{array}{l}\text { Draft at least three } \\
\text { reflection activities for } \\
\text { your class; Read Rodgers } \\
\text { (2002), Desjarlais \& } \\
\text { Smith (2011), and } \\
\text { Graessner (2009); } \\
\text { Submit 25-word } \\
\text { summaries of papers. }\end{array}$ \\
\hline $\begin{array}{l}\text { Activity } \\
\text { Presentation }\end{array}$ & $\begin{array}{l}\text { Share perceived challenges and } \\
\text { strengths with current activity } \\
\text { drafts; I ncorporate feedback } \\
\text { from the group to address } \\
\text { activity objectives; Engage in } \\
\text { solution-finding with peers } \\
\text { regarding their activities. }\end{array}$ & $\begin{array}{l}\text { Submit a poster of the } \\
\text { content in the provided } \\
\text { format; I dentify research } \\
\text { questions of interest. }\end{array}$ \\
\hline $\begin{array}{l}\text { Assessment } \\
\text { Workshop }\end{array}$ & $\begin{array}{l}\text { Identify at least three different } \\
\text { strategies that could be used to } \\
\text { assess the success of their } \\
\text { activity; I dentify at least one } \\
\text { mechanism to assess the } \\
\text { research question of interest } \\
\text { (for those that desire to } \\
\text { publish). }\end{array}$ & $\begin{array}{l}\text { Read Kember et al. } \\
\text { (2008), Moon (2006), } \\
\text { Stewart \& Richardson } \\
\text { (2000); Specify desired } \\
\text { information about student } \\
\text { thinking as a result of the } \\
\text { reflection activity. }\end{array}$ \\
\hline $\begin{array}{l}\text { Activity } \\
\text { Presentation }\end{array}$ & $\begin{array}{l}\text { Share perceived challenges and } \\
\text { strengths with current activity } \\
\text { drafts; I ncorporate feedback } \\
\text { from the group to address } \\
\text { activity objectives; Engage in } \\
\text { solution-finding with peers } \\
\text { regarding their activities. }\end{array}$ & $\begin{array}{l}\text { Submit a poster of the } \\
\text { content in the provided } \\
\text { format; I dentify research } \\
\text { questions of interest. }\end{array}$ \\
\hline $\begin{array}{l}\text { Sustaining } \\
\text { Activities }\end{array}$ & $\begin{array}{l}\text { Present three-minute pitch to } \\
\text { group; Present the portfolio of } \\
\text { reflection activities developed } \\
\text { over the summer (including }\end{array}$ & $\begin{array}{l}\text { Revise the three-minute } \\
\text { pitch based on the refined } \\
\text { activities. }\end{array}$ \\
\hline
\end{tabular}




\begin{tabular}{lll}
\hline Session & Session Objectives & Pre-Meeting Homework \\
\hline $\begin{array}{l}\text { Sustaining } \\
\text { Activities }\end{array}$ & $\begin{array}{l}\text { assessment plan); Brainstorm } \\
\text { ideas to sustain and broaden } \\
\text { the development, refinement, } \\
\text { and use of student reflection } \\
\text { activities. }\end{array}$ & \\
$\begin{array}{l}\text { Poster } \\
\text { Dissemination }\end{array}$ & $\begin{array}{l}\text { Describe reflection and the } \\
\text { target activity to a naïve } \\
\text { audience; Argue for reflection } \\
\text { as a high-impact practice to } \\
\text { peers. }\end{array}$ & $\begin{array}{l}\text { Prepare a poster for } \\
\text { printing; Revise the three- } \\
\text { minute pitch based on the } \\
\text { refined activities. }\end{array}$ \\
\hline
\end{tabular}

Desjarlais, M., \& Smith, P. (2011). A comparative analysis of reflection and selfassessment. International J ournal of Process Education, 3, 3-18.

Felten, P., Bauman, H.-D. L., Kheriaty, A., \& Taylor, E. (2013). Cultivating growth: Conversation in community. In Transformative Conversations (pp. 31-62). San Francisco, CA: Wiley.

Graessner, A. C. (2009). Inaugural editorial for Journal of Educational Psychology. Journal of Educational Psychology, 101, 259-261.

Moon, J. A. (2006). Assessing journals and other reflective writing. In Learning Journals: A Handbook for Reflective Practice and Professional Development (pp.107-121). New York, NY: Routledge.

Stewart, S., \& Richardson, B. (2000). Reflection and its place in the curriculum on an undergraduate course: Should it be assessed? Assessment \& Evaluation in Higher Education, 25, 369-380. 


\section{Appendix B}

Reflective Professional Writing Portfolio Assignment Sheet (Condensed Version)

\section{Overview}

Electronic portfolios are an increasingly common vehicle for developing a professional online identity. Employers are interested in e-portfolios for a variety of reasons: they provide multiple writing samples, display skills with technology, design, and new media, and require reflection and meta-knowledge. Professionals like e-portfolios because they help them keep track of their projects and accomplishments. As a final course assignment, you will design an e-portfolio using a platform of your choice. The portfolio will highlight your writing from your discipline complemented by writing you do in this course. You will create your eportfolio for an audience of potential employers.

\section{Objectives}

- To select and reflect on your previous writing experiences in light of our course discussions

- To articulate what constitutes good communication in various contexts in your discipline

- To organize and interpret your writing artifacts for an audience of potential employers

- To apply your knowledge of design to an online environment

- To describe your identity as a writer, now and in the future

\section{Artifacts and Abstracts}

Your portfolio will include at least three examples of your writing or design work from your discipline. They may be individually- or group-authored, but if you choose a group-authored work, you need to be prepared to describe your role in the project. Good artifacts will demonstrate the range of your skills as a writer, designer, and/or communicator and will allow you to discuss your strengths and/or your improvement as a communicator.

Each artifact will be accompanied by an abstract that contextualizes and reflects on your artifact for an audience of potential employers. The most successful abstracts will

- explain the artifact (audience, purpose, context, scope, date, client, etc.)

- identify specific examples of good writing, design, or communication within the artifact and how you achieved those

- analyze why those examples demonstrate good communication in your discipline (in other words, why is it important that you can do the thing you've identified well) and what those examples say about you as a communicator

\section{Communication Philosophy}

In addition to your individual abstracts, your portfolio will also include a document that reflects on the portfolio as a whole and helps a reader understand the portfolio in the larger context of your past development and your future goals.

In approximately 500 words, you will write a communication philosophy that synthesizes the pieces of your portfolio to explain your identity as a scientist/engineer/mathematician who is also a writer/speaker/designer. Portfolios should demonstrate all the features of good writing we've discussed this quarter, including clarity, concision, and downshifting to include specific examples. The most successful philosophy statements will include 
- an introduction that explains the purpose of the reflection and previews the organization of the rest of the document

- a reflective section that uses specific examples from the portfolio to demonstrate what you've learned about yourself and your strengths as a communicator from the portfolio. In other words, now that all of this work is together in one place, what does it show about you? What themes have developed in your work? What claims can you make about your approach to communication tasks?

- a forward-looking section that addresses the ways you imagine yourself continuing to apply and/or build upon these skills. What projects would you like to do more of in the future? What areas would you like to continue to develop? How can what we've seen here translate into your future career path?

\section{Assessment}

You will be given informal feedback on your progress (particularly your abstracts) by your peers and me throughout the quarter. You are also welcome to see me in my office to discuss any part of this project. Your final project will be assessed according to the specifications set forth in the Portfolio Rubric. Your choices of what to include in your portfolio and the amount of time you spend on writing and design will determine your final grade. 


\section{Appendix C}

Fundamentals of Heat \& Mass Transfer Prediction Activity and Follow-Up Questions

\section{I n-Class Activity}

Make a prediction...

Both cups contain the same volume of water at room temperature. To one you add regular ice cubes, and to the other one you add SONIC ${ }^{\circledR}$ ice (crushed ice). Each cup will contain the same mass of ice. Assume no heat is gained/lost to the surroundings and no bulk-motion.

On your own, make the following predictions:

1. Which scenario will have a higher rate of heat transfer? What will you observe (visually see or measure) that confirms this? Explain why you made this prediction.

2. Once all the ice has melted, which scenario will have transferred more heat? What will you observe (visually see or measure) that confirms this? Explain why you made this prediction.

\section{Follow-Up Questions}

1. Recall the prediction activity in-class. Re-state your initial prediction below, including written explanation why you made this prediction. (2-3 sentences)

2. What happened in the activity? Describe the result you observed in 2-3 sentences.

3. Compare your initial prediction to what actually happened in the activity. Were your predictions completely correct? Yes / No

4. Please explain your selection from Question 3. In your explanation, you should pay particular attention to why your original predictions were correct or not correct and how you revised your thinking to explain what happened. If you made a correct prediction and revised your justification as to why you made that prediction in any way to include new ideas, mechanisms, models, or parameters, be sure to explain this.

5. Do the factors that increase the rate of heat transfer always increase the amount of heat transfer? Yes / No

6. Please explain your selection in Question 5. (2-3 sentences)

7. Given what you learned from this activity, answer the following question related to mass transfer: Do the factors that increase the rate at which a sugar cube dissolves in water always increase the final amount of sugar dissolved in water at equilibrium.? Yes/ No

8. Please explain your selection in Question 7. (2-3 sentences)

9. What, if anything, did you learn from this activity? 
Summers earned her PhD in Rhetoric and Composition at Pennsylvania State University in 2014 and joined the RHIT faculty in 2014. Her work focuses on writing in the disciplines, particularly at the advanced undergraduate and graduate levels. She teaches courses in writing and engineering communication, including technical and professional communication, intercultural communication, digital writing, and grant writing.

Chenette earned her PhD in chemical engineering at Clemson University in 2014, and joined the RHIT faculty in 2014. Her work focuses on membrane materials, bioseparations, and engineering education research. She teaches courses in heat and mass transfer, bioseparations, and chemical engineering laboratory. Chenette is a graduate of the National Effective Teaching Institute, sponsored by the American Society for Engineering Education.

Ingram earned her PhD in biology at Indiana University in 2004, and joined the RHIT faculty in 2004. Her work focuses on ecology and evolution, especially in the context of student research. She teaches courses in ecology, scientific research methods, evolutionary medicine, and critical thinking. Ingram currently serves as the Director of RHIT's Center for the Practice and Scholarship of Education.

McCormack earned his PhD in mechanical engineering at Carnegie Mellon University in 2003, and joined the RHIT faculty in 2013. His work focuses on design methodology and computational design. He teaches courses in design at both the introductory and senior level, lean manufacturing, and design for manufacturing. McCormack has published frequently in the realm of engineering education, including teaching ethics and evaluating professional skills.

Cunningham earned his PhD in mechanical engineering at Purdue University in 2006 and joined the RHIT faculty in 2006. His work focuses on engine and emissions monitoring and control. He also conducts education research on engaging students in their metacognitive awareness and skill development. He teaches courses in mechatronics, measurement systems, and analysis of engineering systems. Cunningham recently completed a sabbatical year as a scholar in the Department of Engineering Education at Virginia Tech. 